\title{
The Role of Knowledge Management in Innovative Supply Chain Design
}

\begin{abstract}
This exploratory research examined the contribution of knowledge management (KM) to supply chain management (SCM) and its specific role in supply chain design. Following a review of relevant literature, a conceptual model was developed to indicate the knowledge domains involved in an innovative approach to supply chain design. The contributions of KM are investigated and analyzed through a case study of supply chain design in the Australian beef industry. While KM supported supply chain design through various KM processes such as knowledge acquisition, sharing, dissemination and protection, the most significant contribution came from the process of knowledge integration. This indicates the significant potential of KM to play a major role in supporting the complex nature of contemporary supply chain design.
\end{abstract}

\section{Introduction}

Increasingly, modern supply chains are viewed as a significant source of value to organizations. The strategic management of the supply chain has the potential to deliver value to customers and other stakeholders, as opposed to simply providing inputs, goods or services [1]. Particularly from a resourcebased theory perspective, supply chains have the potential to represent a source of sustained competitive advantage [2]. The contemporary field of supply chain management (SCM) is undergoing major changes, characterized by business practices that have become strategic rather than tactical in approach, thus increasing challenges for managers [3]. In today's global business environment, markets become more turbulent and competitive as product and service lifecycles shorten, thus creating greater uncertainty and potential risk. As supply chains become increasingly lengthy and complex, the strategic potential of effective SCM has never been greater [3] [4] [5]. However, SCM involves many layers of complexity, including cross-border flows of goods, services, investment, as well as intellectual and human capital that is still challenging and poorly understood by managers, economists, policy makers and other experts [6]. Babin and James [7] explore the concept of value as an essential element of managerial strategy because of its capacity to deliver value to customers.
In a service economy, supply chain management is largely driven by end user customers and delivered through complex value networks [8]. The extent to which organizations can harness this value will determine the level of their success in creating sustained competitive advantage. The strategic management of supply chains can create value for customers and other stakeholders [9]. However, the success of creating sustainable competitive advantage in SCM is highly dependent on knowledge and the extent to which it is effectively managed.

The many components of every supply chain comprise decisions that can be made about the supply chain design, which are intimately connected to the sources of uncertainty that relate to these choices. Successful supply chain design involves the deployment of assets in ways to enhance profitability and deliver value to stakeholders. Designing an optimal supply chain network involves decisions such as facility location, capacity, technology and many others, which must be connected to uncertain quantities such as demand uncertainty, supplier reliability, quality of inputs, and equipment reliability. To design supply chains that effectively deliver to a business strategy and market requirements, an integrated approach is required that simultaneously considers choices about supply chain design parameters and these sources of uncertainty. Effective SC design also incorporates measurement of SC effectiveness, using both SC operating value parameters as well as business value parameters. Such complex forms of decision-making are highly dependent on knowledge and knowledge processes, such as knowledge acquisition, sharing, dissemination and measurement and effective management of that knowledge. This paper investigates the extent to which knowledge management (KM) adds value by contributing to effective SCM in general, and supply chain design in particular.

\section{Literature Review}

The potential of the supply chain to add significant value lies in the manner in which it is designed and the decisions made by managers as to the structure, flow and stakeholders involved. Decisions can affect not only the cost of a product or service, but also an organization's ability to respond to market changes, to 
innovate and to develop new offerings. Those who do it well gain competitive advantage that leads to sustainable and long-term business performance advantage. For the purposes of this paper we adopt the following definition of SCM: " $a$ set of approaches utilized to efficiently integrate suppliers, manufacturers, warehouses, and stores, so that merchandise is produced and distributed at the right quantities, to the right locations, and at the right time, in order to minimize system wide costs while satisfying service level requirements." [10].

The supply chain is positioned at the heart of Porter's (1985) Value Chain Model [11]. Porter's model is based on the premise that organizations are not just a random combination of tangible and intangible resources; indeed, these resources will only add value if they are arranged in a systematic manner, and organizations that manage the linkages across various activities will achieve greater levels of competitive advantage. In addition to Porter's model, Treacy and Wiersema provide a useful approach to consider market positioning and business model design, that then relates to resources, investments and supply chain design priorities [12]. The supply chain represents a complex and dynamic set of interactive activities and processes, often characterised by conflicting objectives in various parts of the supply chain network. As such, supply chain design decisions cannot be developed in isolation, as effective strategies need to be integrated across the entire supply chain [10]. Fine [13] advocates that SC design should take into account both product design and production system design as part of an effective SC strategy. Lyons and Ma'aram [14] suggest that close alignment between business strategy, SC strategy and market requirements is needed in order to gain competitive advantage from a firm's SC configuration. In order to achieve maximum value, making decisions based on a SC strategy linked to the overall business strategy requires integration and a holistic perspective, and a growing body of literature speaks to the need for such linkages [15] [16].

Indeed, there is no shortage of decision models or frameworks for guiding supply chain design and decision making, particularly under uncertainty [16] [17] [18] [19] [20] [21]. A study by Yildiz et al. [22] attempts to reconcile and integrate the dual (and often conflicting) objectives of minimising costs and maximising reliability in the context of supply chain design formulation. Others advocate the use of supply chain network design to determine the structure of the supply chain and make decisions regarding facility location and size, inventory management, distribution and transport [23]. Supply chain management can only deliver value when it is based on planning and is closely aligned to an organization's strategic priorities [24]. Decisions must be made with regard to all aspects of the supply chain, from procurement to logistics and through to the customer. Besides considering the external business and political environment, design decisions include social, behavioural and structural elements of the supply chain, as well as those relating to inventory, transport, capacity and technology.

\subsection{Knowledge Management and SCM}

Knowledge has long been considered a strategic resource in SCs [25]. According to Samuel et al 2011, [26] KM is a major enabler of SCM, critical to information and knowledge intensive global enterprise environments. As SCM has grown in significance with the spread of globalization, competition between SCs becomes an important driver of KM efforts to support SCM. In turbulent and highly competitive environments, they argue that KM can assist with exploring new trade-offs and developing new organizational models to enhance decision making and maintain a competitive edge. SCs can be seen as configurations of firms working together that continuously need to upgrade capabilities and performance in order to stay competitive. These networks are made up of heterogeneous groups sharing common points of interest. Successful SCM involves the ability to quickly utilise/mobilise the entire network of suppliers, vendors, buyers and customers. This becomes a major role for KM, since flows of knowledge and information lie at the core of coordination and collaboration [26]. This provides an opportunity to build knowledge based tools that form an important part of 'the extended firm's capabilities.

Indeed, KM in SCM reflects a rapidly growing area of academic and managerial interest. In an extensive literature review of KM and SCM covering the years 2001-2015, Bhosale and Kant identified main areas of research interest [27]. These included various KM processes such as knowledge acquisition, knowledge integration, knowledge protection, knowledge innovation and knowledge dissemination. Their study revealed that the major KM issues focused on were knowledge sharing, KM systems, knowledge transfer, knowledge flows and KM and IT. Dominant SCM issues include SC performance, SC relationships, SC integration, product innovation, IT in SC, SC collaboration, and SC networks. Their study reflects a fairly broad range of issues linking $\mathrm{KM}$ and SCM, and demonstrating, from a KM perspective, the ways in which KM contributes to effective and strategic SCM. It is interesting to note that more than $90 \%$ of the articles they include in their literature review were published between 2006-2014, thus indicating that this is a growing area of interest. 
However, supply chain design is not an area that garners much coverage in the KM/SCM literature. Another review of literature by Marra et al [28] indicated that KM plays an important role in implementing SCM., such as in knowledge capture, knowledge organization, knowledge integration, and for improving collaboration. While their study identified 58 articles on KM and SCM, they found a lack of research on measuring the impact of $\mathrm{KM}$ practices on SC performance, on knowledge accumulation processes, on decision support and supply chain design issues. Clearly there is a gap in the literature on KM and SC design issues, so this is an area that warrants further investigation.

There is a broad base of literature concerning KM processes such as knowledge acquisition, knowledge transfer and sharing, as well as knowledge dissemination and their contribution to SCM. Data capture, information mining and knowledge capture in SCM can increase an organization's ability to adjust to changes in the environment [29]. For Pan et al. [30], the main KM activities related to SCM consist of knowledge sharing, knowledge transfer, knowledge creation and learning. In their view, the key to success of KM activities is being able to capture knowledge effectively and to transfer knowledge into new products, services and technologies. Another study suggests that KM can increase SC flexibility through enhanced internal and external knowledge transfer activities. Knowledge transfer to support SCM is particularly effective in contexts characterized by high complexity [31]. In environments where knowledge (rather than information) is critical, both internal and external knowledge transfer is essential to fostering SC flexibility. Another study found that data capture, information mining and knowledge capture across the SC can increase an organization's ability to successfully manage change [29]. Yang [32] found that KM processes such as knowledge acquisition and dissemination lead to higher levels of performance in buyer-supplier collaborations. Cai et al. [33] highlight the role of $\mathrm{KM}$ in enhancing knowledge sharing, particularly with respect to issues of power and the mediation of trust in SC relationships. Others point to the importance of knowledge sharing and re-use in SCM [34]. The identification, modelling and explicit representation of knowledge can support knowledge sharing and collaboration by developing a supply chain wide knowledge ontology and vocabulary - a commonly understood language around knowledge [35]. On the issue of SC collaboration, Cao et al. [36] found that collaboration involves creating ideas and value together - rather than merely exchanging information - and this is an area where KM can add value though knowledge development and good communication. Another study found that knowledge sharing and enrichment activities can lead to enterprise-wide knowledge integration in collaborative SCs [37].

On the operational side, KM can promote better utilization of resources to increase productivity and support sustained forms of competitive advantage [38]. KM can improve operational performance, through activities such as product design optimization, thereby improving SC efficiency [39]. Biotto et al [40] found that $\mathrm{KM}$ processes that enhance cultural diffusion along the SC can drive product quality improvement initiatives. KM can also improve agility, adaptability and alignment of SCs [41]. Other studies have found that SC integration enhances agility through knowledge-based systems that respond to the complexity of the SC and provide critical information leading to rapid strategy formulation [42]. KM creates value through enabling greater transparency in the SC, focusing on customer needs, value propositions and the creation of value through combining skills, knowhow and experience [43]. Through supporting knowledge development, KM assists in fostering a culture of competitiveness that leads to more strategic and higher performing types of SCM [44]. Indeed, converting knowledge resources into useable KM capabilities can enhance competitive advantage [29]. A study by Beske et al. [45] found that KM supports the development of dynamic capabilities to encourage sustainable SCM practices in the food industry.

Some of the literature focuses on the role of KM in achieving successful SC integration. [28] [37] [46]. $\mathrm{KM}$ can be used to build and enhance structured forms of communication that can support SC integration, leading to greater levels of business performance, particularly in SCs characterized by high levels of complexity [47]. Moreover, KM positively moderates the relationship between integration and performance. Liu et al. developed a global knowledge chain management framework to support collaborative decision making in lean SCs. Their work also found that KM can enhance global SC integration and can improve decision making and 'time-to-decision' processes. KM can also help with navigating contextual forms of knowledge from both the demand and supply sides in global SCs [48]. While the literature concerning the relationship between KM and SCM is well established and indeed growing quite rapidly, there is a pronounced gap of studies relating specifically to the area of KM and SC design.

\section{Methodology}

This study is underpinned by two complementary theoretical perspectives - the resource based view 
(RBV) and the knowledge based view (KBV). In both instances, resources at the base of a firm's capabilities provide the foundation for competitive advantage. In the RBV of organizations, knowledge is considered an essential resource [49] [50], and success is dependent on the ways in which organizations develop and deploy their knowledge resources and capabilities [51] [52] [53]. Similarly, in the KBV, knowledge is regarded as the key resource, where the creation, integration and application of knowledge is at the core of the firm, stressing the role of knowledge in developing organizational capabilities to create sustainable competitive advantage [54] [55] [56]. Since the RBV and the KBV take a holistic view across business functions in a firm, they are well suited to the study of complex phenomena such as knowledge management.

This exploratory research explores the ways in which KM can contribute to SCM in general, and SC design in particular. Following a review of the literature on KM and SCM, a conceptual model was developed to depict the various stages of the SC design process where there are distinct knowledge domains and where KM has the potential to contribute to SC design. For the purposes of this paper, knowledge domains represent the content of a particular field of knowledge, or knowledge used to refer to a particular specialized discipline - in this case, SC design. Based on previous research that proposes an innovative and holistic approach to SC design [57], the conceptual model identifies distinct stages of the SC design process, and indicates the various knowledge domains that are represented in the process. The next stage of the research involved a case study to examine the role of $\mathrm{KM}$ in the development of a supply chain for the beef industry in Australia. This study adopts a qualitative methodology in the form of a single intensive case study. The application of a case study methodology, used in social science research, was chosen for this study because case study research is highly appropriate in settings with a variety of overlapping contexts and discourses. The robustness of case study approaches is dependent on the careful selection of appropriate cases as well as the application of relevant case study principles and practices. Despite criticisms of the case study approach concerning its lack of reliability, the legitimacy of case studies is enhanced when the subject matter has indistinct boundaries and varying contexts [58] [59]. The company chosen for this case study was selected as part of a purposive sampling methodology to ensure we learned as much as possible from this exploratory research. The company already had a long history of success in the domestic beef industry, with well-established supply chains and capacity for risk analysis under conditions of uncertainty. However, they were only just beginning to consider a move into export of their beef products to China. A content analysis technique was used to analyze data gathered through in-depth interviews with the firm owner, board directors, senior managers and other stakeholders. Lasting between 1.5 and 3 hours, these in-depth interviews yielded multiple perspectives concerning various aspects of SC design. A method of textual analysis, often used in social science research, utilized a coding system where data was placed into a number of predetermined categories by the researchers and grouped across a range of patterns or themes that emerged from the interviews [59]. For each of the interviews, other documentation was also used to enrich the study, including annual reports, business and government reports, as well as material available in the public domain.

The case study presented in this paper is the beginning of what we intend as longitudinal research with this particular firm, as their export strategy and SC design strategies unfold. The researchers are also undertaking ongoing research across a range of firms currently designing SCs with a view to exporting from Australia to China. It is anticipated that this further research will generate a large number of case studies that will allow for cross-case analysis and generalizability of results.

\section{Findings and Discussion}

Global SCM involves a complex interaction of various supply chain elements that, if effectively managed, can deliver value across a number of dimensions including cost, quality, delivery, flexibility and innovativeness. In a business context, these value dimensions translate into sales, market share, cash flow and profitability. The chosen strategy or approach to product design, including the level of quality, flexibility, degree of customisation and product complexity will have implications for the supply chain. In developing a supply chain strategy, various decisions must be made across the length and breadth of the supply chain, including a range of supply chain decision elements, including capacity; technology; process choice; location; push v pull; procurement; sustainability; raw materials; HRM; customers; quality; and inventory management. These decisions should preferably be made in a manner such as to achieve fit between them, and this coherence should be aimed at achieving the best overall outcome, of specific business strategy and advantage. The effective management of knowledge is critical to each of these steps [57]. 


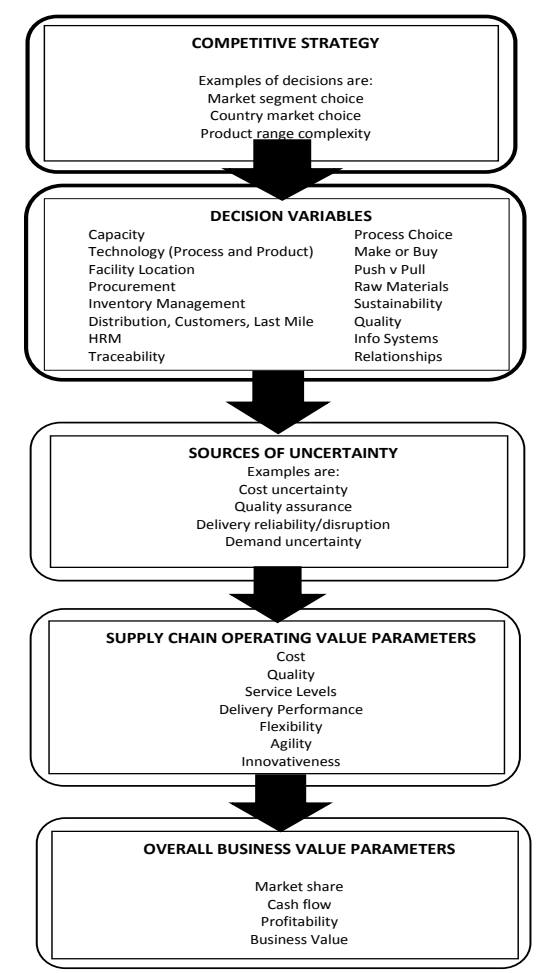

Figure 1. Knowledge Domains in the SC design process

Certain decision variables need to be taken into consideration when designing a viable supply chain, and various sources of uncertainty also need to be evaluated. Each of these supply chain elements are interconnected and interrelated, so decisions relating to one element will most likely have an impact on other supply chain elements. Inevitably, certain tradeoffs occur when decisions are taken concerning the adoption of a particular operational and supply chain strategy. These trade-offs can impact a number of value elements including cost, quality, delivery, flexibility or customization [57] [60]. The context and level of uncertainty will differ across the various decision elements relating to supply chain strategy. Similarly, different trade-offs will apply across these elements. Examples of uncertainty include demand uncertainty and cost uncertainty. Supply chain reliability can also be best expressed in terms of measures of uncertainty. These disparate elements that illustrate the connectedness of supply chain decision categories and their relatedness to sources of uncertainty, involving both primary and secondary elements, illustrate both the richness and the complexity of integrating an end-to-end supply chain design.

Figure 1 depicts the various steps of the SC design process and the knowledge domains pertaining to each of these steps. For the purposes of this paper, knowledge domains represent the content of a particular field of knowledge, or knowledge used to refer to a particular specialized discipline - in this case, SC design. Following Figure 1, the first step of the SC design process is to specify the business strategy and market positioning, customer profile and prioritized performance goals. For example, is the intended supply chain going to be supplying a highly differentiated market segment or a mass (middle) market or 'no frills' segment? In this stage, knowledge acquisition, sharing and integration will guide the process of determining priorities and decisions in the supply chain. What are the competitive order winning priorities in the market segment, chosen usually from cost/ low price, quality, service, flexibility, innovation, customization, delivery performance and other potential priorities? From these desired outcomes, and the desired market place or space, the supply chain can then define its goals. This involves a variety of decision variables that must be considered in view of the intended competitive strategy. These include decisions regarding raw materials and other inputs, then the decision variables must be considered and shortlisted, including decision elements such as facility location, capacity, processing, storage and transport options. Each stage of the decision process will ultimately involve certain tradeoffs between the elements [57]. The third step involves considering the many sources of uncertainty within the decisions that comprise supply chain design. These range from cost uncertainty, supply chain component uptime reliability, demand uncertainty, quality risk factors, and raw material availability. The fourth step involves taking into consideration various decision scenarios and evaluating them against a range of supply chain operating value parameters, including cost, quality, service levels, delivery performance, flexibility, agility and innovativeness. This includes fine-tuning and further option generation of the many and various supply chain components until a solution is designed and evaluated that is considered to be the best one available. This might take much iteration in a complex supply chain design scenario. Such a 'decision aided' process has the potential to substantially improve on purely intuitive approaches to supply chain integration and explicit uncertainty consideration. The final step is to consider various options again overall business value parameters, which include market share, cash flow, profitability and business value. 
The 'art' of supply chain design lies in bringing together the key decision parameters, the sources of uncertainty, and the desired and prioritized performance outcomes, that drive the organization's ultimate goals, be those profits or other outcomes, such as environmental or social outcomes. This supply chain design process cannot be fully programmed into a precise mathematical formulation that is amenable to an optimization routine, because it is relatively unstructured. It requires lateral thinking inputs, and the distinct choices within each element are discrete and categorical variables, which are different in every instance. We have proposed a staged process in which the steps comprise shortlisting of candidate supply chain designs, evaluated with Monte Carlo simulation procedures, in an iterative process [57]. A supply chain design process that fully integrates risk and performance management aspects, and further that takes in the many interactive effects and influences across the sixteen or so supply chain decision categories, can be specified as a human - machine combined process. On the one hand, there is far too much detail and complexity for the human brain to do it unaided, as if it were a pure or black art, and on the other hand, there is a lack of structure and too many first and second order interactions to specify a fully automatable optimization routine. As such, we propose a combined approach. There is a significant role to be played by knowledge management across all stages of the supply chain design process described above, from relatively simple processes such as knowledge acquisition, to more sophisticated forms of $\mathrm{KM}$ such as knowledge collaboration and knowledge integration.

\subsection{Case study: applying the comprehensive supply} chain design approach to a complex choice process A group of growers in the Australian beef industry, became dissatisfied with the arrangements with the local abattoir, and decided to investigate exporting their premium quality product to Chinese high-end markets, or else to use another local or overseas processor. After conducting market research (KM step1), they faced the task of designing the supply chain. The market research gave them the confidence that the exports would command premium prices, if a supply chain could efficiently provide delivery to those markets of their premium quality beef cuts. Major decision parameters were the market and business strategy (KM step 2), followed by the core supply chain decisions regarding assets and sizing the market and supply response, and deciding where to do the processing and storage (KM step 3). This included choices of whether to do all the processing near the farms, near the Chinese markets, or to split them and do some processing in Australia, with bulk carcasses or 'quartered' product being sent to China for final processing and packaging. Chilled or frozen beef supply chains were possible alternatives. These choices would have major influences on quality, cost, service and inventory levels and, in turn, facility location (KM step 4). Demand uncertainty was high, as was the achievement of high levels of quality, responsiveness, and supply chain and transport reliability, particularly if low cost Chinese processing was to be preferred to higher cost processing in Australia. Choices of where to do what level of processing relate to service levels for clients, and immediately raised the issue of inventory, meaning where it should be stored and what levels will be required to achieve reliable supply. The intended market was for high-end hotel chains, restaurants and elite supermarkets, hence supply reliability was a critical order winner, as was quality (KM step 5). It was also considered that a value adding 'direct to consumer' channel could be created using one of many options for solving the 'last mile' challenge in Chinese cities.

After extensive consideration of alternatives and qualitative evaluation of many alternatives, and risk factors, an initial shortlist of five alternatives of capacity, facility location, transport, distribution and inventory options was created, as was a list of the uncertainties in performance, demand, supply reliability, quality and cost associated with each one of those (KM step 6). A deterministic model was first created and validated. This was done with the human decision makers engaged in the project conducting both qualitative discussions, analyses and iterating with spreadsheet analyses which used point estimates only (KM step 7). Initially, risk analysis was not used in early screening processes. Probabilities were assessed for these sources of uncertainty under each major scenario (KM step 8). Choices of process and technology were then considered, being to use chilled versus frozen beef transport and logistics, and to ship all product, versus air-freighting some high value beef cuts. Relevant elements of uncertainty were cost, quality and lead times, for which probability distributions were assessed, in the light of all relevant information that could be gathered (KM step 9). Push versus pull systems were also considered, for example a finished goods inventory in three major Chinese cities could be a pivot point that was the interface between upstream push (into it), and downstream pull (from it to customers), yet this design parameter interfaced the technology choice (frozen versus chilled), and the customer volume requirements, and hence the capacity offered. There were other options of course, for storage. Three supply chain designs 
were ultimately shortlisted, for full evaluation in a Monte Carlo simulation environment. (KM step 10). These shortlisted 'scenarios' were:

Option 1: - full processing of the beef into finished product near the source in Australia, and direct shipping to partner wholesalers in China for sale and distribution.

Option 1A, where not all of the beef products would be exported, but that the low value cuts of beef would remain in Australia for local retail markets, with the premium (high price) cuts going to China.

Option 2: - This would involve early stage processing of the beef, such as 'quartering', near the Australian farms, then transport of these to Chinese markets for further and final processing and packaging

Option 3: - Fully (chilled) carcass shipment to Chinese processing facilities

Through the use of KM processes, extremely useful insights were created that influenced the realworld decisions: option 1A was chosen although it was of highest expected cost, because it was also of lowest uncertainty. A low uncertainty approach, still bringing solid profit margins was preferred to other potentially higher margin options, which would incorporate significantly higher uncertainty levels, and indeed be high in their levels of uncontrollable factors. Moreover, it became apparent that if a largely deterministic approach had been taken, a different option would likely have been chosen, and that the riskiness of the chosen option would have been under accounted for. This in itself fully justifies the approach of explicitly taking a probabilistic approach, and of applying this methodology to an end-to-end design evaluation.

In summary, the Monte Carlo analysis was used to combine the design variables and the probabilistic assessments, and these were able to combine the shortlisted designs, and separately create input and then output probability distributions for cost, quality and delivery performance. From the first cut of such analyses, it was then possible to iteratively fine tune the design parameters, and check the sensitivity of the output distributions to input choices and to changes in the assessed uncertain quantities. The iterative process and the probabilistic Monte Carlo models provided many benefits to the SC designers/owners, particularly coming from the explicit consideration of interactive effects of the various supply chain elements, and the explicit assessment of sources of uncertainty using probabilities. Without such an approach, uncertainties are usually under-accounted for, or risk is separately considered as a purely operational matter (for example SC disruption risk only), rather than as a strategic design input. This approach allowed the supply chain design process to fully consider the full gamut of possible outcomes, limited only by the quality of the inputs and assessments. It fully integrated the risk and performance aspects of supply chain design. This approach was considered to have effectively integrated human elements of judgement and decision making, with the power of the risk analysis approach. It was considered likely that if the combined human judgement and risk analysis approach had not been applied, that a different option would likely have been chosen, that may well have under-accounted for the riskiness of some options. The case study illustrates the practicality and decision making power of how a risk analysis approach can support human judgement to effectively combine performance and risk aspects of supply chain design. The case study also highlights the significant contribution that KM can make to the process.

\subsection{KM contribution to SC design}

The case study indicates ten points at which KM processes contributed to the supply chain design process. These KM processes were sourced from the literature on KM and SCM and reflect the dominant ways in which the relationship between KM and SCM is represented in the literature [27] [28]. SC design is heavily dependent on knowledge acquisition to inform the preliminary stages of the design process - for instance, in gathering market research. Knowledge creation also formed a contribution - because each SC is unique, new knowledge is created in the SC design process. Since SCs reflect value and are a source of competitive advantage, the intellectual property created needs to be protected, and KM provides the mechanisms to protect IP. Knowledge dissemination forms a rather benign part of KM's contribution to SC design. By far, knowledge integration was the major $\mathrm{KM}$ contributor in the SC design process as reflected in the case study - success of KM initiatives were most dependent on knowledge integration to support decision making, evaluation and synthesis of the options generated. It was found that knowledge sharing and knowledge collaboration were vital KM support processes to support knowledge integration. Table 1 provides an overview of KM contributions to SC design. Based on the literature review, we have listed the most predominant KM processes that support SCM, and highlighted which of these were most prevalent in the case study. 


\begin{tabular}{|c|c|c|c|c|c|c|c|}
\hline $\begin{array}{c}\text { KM STEP \& } \\
\text { SC DESIGN } \\
\text { ACTIVITY }\end{array}$ & $\begin{array}{c}\mathrm{K} \\
\text { acq }\end{array}$ & $\begin{array}{c}\mathrm{K} \\
\text { cre }\end{array}$ & $\begin{array}{c}\mathrm{K} \\
\text { shar }\end{array}$ & $\begin{array}{c}\mathrm{K} \\
\text { coll }\end{array}$ & $\begin{array}{c}\text { K } \\
\text { int }\end{array}$ & $\begin{array}{c}\mathrm{K} \\
\text { diss }\end{array}$ & $\begin{array}{c}\mathrm{K} \\
\text { prot }\end{array}$ \\
\hline $\begin{array}{l}1 \\
\text { market } \\
\text { research }\end{array}$ & $\square$ & & $\square$ & & & $\square$ & \\
\hline $\begin{array}{l}2 \\
\text { Business } \\
\text { strategy } \\
\text { decision }\end{array}$ & & & & $\square$ & $\square$ & & $\square$ \\
\hline $\begin{array}{l}\mathbf{3} \\
\text { Processing \& } \\
\text { storage } \\
\text { decision } \\
\end{array}$ & & & & $\square$ & $\square$ & & \\
\hline $\begin{array}{l}4 \\
\text { Consider } \\
\text { decision } \\
\text { elements } \\
\end{array}$ & & & & & $\square$ & & \\
\hline $\begin{array}{l}5 \\
\text { Quality } \\
\text { issues }\end{array}$ & & & & & $\square$ & & \\
\hline $\begin{array}{l}6 \\
\text { Shortlist } \\
\text { alternatives }\end{array}$ & $\square$ & & $\square$ & & $\square$ & & \\
\hline $\begin{array}{l}7 \\
\text { Qualitative } \\
\text { iterations } \\
\end{array}$ & $\square$ & & $\square$ & $\square$ & $\square$ & & \\
\hline $\begin{array}{l}8 \\
\text { Uncertainty } \\
\text { assessment } \\
\end{array}$ & $\square$ & & & $\square$ & $\square$ & & \\
\hline $\begin{array}{l}9 \\
\text { Cost/ } \\
\text { Quality } \\
\text { assessment }\end{array}$ & $\square$ & & $\square$ & $\square$ & $\square$ & & \\
\hline $\begin{array}{l}10 \\
\text { Final } \\
\text { evaluation, } \\
\text { testing, } \\
\text { decision }\end{array}$ & $\square$ & & $\square$ & & $\square$ & $\square$ & $\square$ \\
\hline $\begin{array}{l}\text { KEY: } \\
\text { K acq-knowl } \\
\text { K cre - knowl } \\
\text { K shar - know } \\
\text { K coll - knowl } \\
\text { K int - knowl } \\
\text { K diss - know } \\
\text { K pro- knowl }\end{array}$ & $\begin{array}{l}\text { Ige aco } \\
\text { ge cre } \\
\text { dge sh } \\
\text { Ige col } \\
\text { ge inte } \\
\text { dge dis } \\
\text { Ige pro }\end{array}$ & $\begin{array}{l}\text { sition } \\
\text { on } \\
\text { ing } \\
\text { oorati } \\
\text { ation } \\
\text { minat } \\
\text { ction }\end{array}$ & & & & & \\
\hline
\end{tabular}

Table 1. Case Study: KM Contributions to SC Design

This preliminary research has implications for SC theory in the sense that it may inform and guide the process of innovative approaches to SC design in the future. From a more practical perspective, the research may highlight areas in which KM practitioners may be able to contribute to SC design. The work may also provide guidance for various SC stakeholders navigating the complex process of SC design, particularly in a global context.

\section{Conclusion}

This exploratory research investigated the potential of KM to contribute to supply chain design. There is a substantial role to be played by KM in terms of enabling, supporting and capturing value from SCM processes and activities. The research has found that KM makes a strong contribution to supply chain design through $\mathrm{KM}$ processes such as knowledge creation, sharing, collaboration and integration. Other $\mathrm{KM}$ processes, such as knowledge acquisition, knowledge dissemination and knowledge protection were less significant in terms of their contribution to the supply chain design process. On the basis of this preliminary research, it would appear that the development of KM as a dynamic capability to support SCM is well warranted. Embedded within the resource-based theory of the firm [61], the notion of dynamic capabilities is well established in the literature as s significant source of competitive advantage, particularly within knowledge intensive organizations. Dynamic capabilities consist of various resources and management strengths that cross cut a range of business functions. Through sensing, seizing and transforming opportunities that arise in the organizational environment, firms gain competitive advantage by continually developing and reconfiguring available resources, both tangible and intangible [62].

KM provides a significant contribution to both SCM and supply chain design, because knowledge reduces uncertainty [63] [64] [65]. Knowledge has the capacity to enhance the decision making process, while at the same time reducing complexity. KM also facilitates the value capture process, because without adequate measurement, evaluation and feedback processes, it is impossible to determine the value created and captured through effective SCM. While this research is preliminary in nature, it forms part of a larger longitudinal study. Further in-depth case studies in the SCM/supply chain design area are already underway, with a view to providing more additional insights through deeper levels of inquiry and cross-case analysis. It is anticipated that further research will unveil and further elaborate on the substantial contributions that $\mathrm{KM}$ can make to the complex area of SCM.

\section{References}

[1] Hammervoll, T. (2009). Value-Creation Logic in Supply Chain Relationships. Journal of Business-to-Business Marketing, 16(3), pp. 220-241.

[2] Barney, J. B. (2012), Purchasing, Supply Chain Management and Sustained Competitive Advantage: The Relevance of Resource-based Theory. Journal of Supply Chain Management, 48, pp. 3-6.

[3] Melnyk, S.A., Lummus, R.R., Vokurka, R.J., Burns, L. and Sandor, J. (2009). Mapping the future of supply chain management: a Delphi study. International Journal of Production Research, 47(16), pp. 4629-4653. 
[4] Von Massow, M. and Canbolat, M. (2014). A strategic decision framework for a value-added supply chain. International Journal of Production Research, 52(7), pp. 1940-1955.

[5] Allesina, S., Azzi, A., Battini, D. and Regattieri, A. (2010). Performance measurement in supply chains: new network analysis and entropic indexes, International Journal of Production Research, 48(8), pp. 2297-2321.

[6] Baldwin, R. and Lopez

chain Trade: A Portrait of Global Patterns and Several Testable Hypotheses. The World Economy, 38(11), pp. 1682-1721.

[7] Babin, B. J. and James, K. W. (2010). A brief retrospective and introspective on value. European Business Review, 22(5), pp. 471-478.

[8] Basole, R. C. and Rouse, W.B. (2008). Complexity of Service Value Networks: Conceptualization and Empirical Investigation. IBM Systems Journal, 47(1), pp. 53.

[9] Estampe, D., Lamouri, S., Paris, J. L. and BrahimDjelloul, S. (2013). A framework for analysing supply chain performance evaluation models. International Journal of Production Economics, 142(2), pp. 247-258.

[10] Simchi-Levi, D., Kaminsky, P. and Simchi-Levi, E. (2008). Designing and Managing the Supply Chain. $3^{\text {rd }}$ ed. Boston: McGraw-Hill.

[11] Porter, M. (1985). The Competitive Advantage: Creating and Sustaining Superior Performance. New York: Free Press.

[12] Treacy, M., and Wiersema, F. (1997). The discipline of market leaders: choose your customers, narrow your focus, dominate your market. Basic Books

[13] Fine, C. (2000). Clockspeed-Based Strategies for Supply Chain Design. Production and Operations Management, 9(3), pp. 213-221.

[14] Lyons, A. and Ma'aram, A. (2014). An examination of multi-tier supply chain strategy alignment in the food industry. International Journal of Production Research, 52(7), pp. 1911-1925.

[15] Ivanov, D. (2010). An adaptive framework for aligning (re)planning decisions on supply chain strategy, design, tactics, and operations, International Journal of Production Research, 48(13), pp. 3999-4017.

[16] Von Massow, M. and Canbolat, M. (2014). A strategic decision framework for a value-added supply chain. International Journal of Production Research, 52(7), pp. 1940-1955.

[17] Azaron, A., Brown, K. N., Tarim, S. A. and Modarres, M. (2008). A multi-objective stochastic programming approach for supply chain design considering risk. International Journal of Production Economics, 116(1), pp. 129-138.

[18] Klibi, W., Martel, A. and Guitouni, A. (2010). The design of robust value-creating supply chain networks: a critical review. European Journal of Operational Research, 203(2), pp. 283-293.

[19] Pishvaee, M. S., Torabi, S. A., and Razmi, J. (2012). Credibility-based fuzzy mathematical programming model for green logistics design under uncertainty. Computers and Industrial Engineering, 62(2), pp. 624-632.
[20] Claypool, E., Norman, B. A., and Needy, K. L. (2014). Modeling risk in a Design for Supply Chain problem. Computers and Industrial Engineering, 78, pp. 44-54.

[21] Govindan, K., and Fattahi, M. (2015). Investigating risk and robustness measures for supply chain network design under demand uncertainty: A case study of glass supply chain. International Journal of Production Economics, DOI 10.1016/j.ijpe.2015.09.033.

Gonzal eł22]] (Yildiz, H., Yoon, J., Talluri, S. and Ho, W. (2016). Reliable Supply Chain Network Design. Decision Sciences, 47 (4), pp. 661-698.

[23] Farahani, R.Z., Rezapour, S., Drezner. T. and Fallah, S. (2014). Competitive supply chain network design: an overview of classifications, solution techniques and applications. Omega, 45, pp. 92-118.

[24] Carter, C. R., and Easton, L.P. (2011). Sustainable supply chain management: evolution and future directions. International Journal of Physical Distribution and Logistics Management, 41(1), pp. 46-62.

[25] Hult, G.T.M., Ketchen, D., Cavusgil, S.T. \& Calantone, R. (2006). Knowledge as a strategic resource in supply chains, Journal of Operations Management 24, pp. 458-475. [26] Samuel, K. E., Goury, M. L., Gunasekaran, A., \& Spalanzani, A. (2011). Knowledge management in supply chain: An empirical study from France. The Journal of Strategic Information Systems, 20(3), pp. 283-306.

[27] Bhosale, V.A., and Kant, R. (2016). "Metadata analysis of knowledge management in supply chain: investigating the past and predicting the future." Business Process Management Journal 22(1), pp.140-172.

[28] Marra, M., Ho, W. and Edwards, J. (2012). "Supply chain knowledge management: A literature review." Expert systems with applications 39 (5), pp. 6103-6110.

[29] Collins, J., Worthington, W., Reyes, P and Romero, M. (2010),"Knowledge management,supply chain technologies, and firm performance", Management Research Review, 33(10), pp. $947-960$.

[30] Pan, Y., Liang, D., Ma, X. and Wang, H. (2013). “A new value stream mapping technique based on material flow, information flow and knowledge flow", Applied Mechanics and Materials, Vols. 397-400, pp 8-11.

[31] Blome, C., Schoenherr, T. and Eckstein, D. (2014) "The impact of knowledge transfer and complexity on supply chain flexibility: a knowledge-based view." International Journal of Production Economics 147, pp. 307-316.

[32] Yang, J. (2013) Harnessing value in knowledge management for performance in buyer-supplier collaboration, International Journal of Production Research, 51(7), pp. 1984-1991.

[33] Cai, S., Goh, M., de Souza, R. and Li, G.(2013) "Knowledge sharing in collaborative supply chains: twin effects of trust and power", International Journal of Production Research, 51(7), pp. 2060-2076.

[34] Scheuermann, A., \& Leukel, J. (2014). Supply chain management ontology from an ontology engineering perspective. Computers in Industry, 65(6), pp. 913-923.

[35] Desouza, K., Chattaraj, A. and Kraft, G. (2003),"Supply chain perspectives to knowledge management: research propositions", Journal of Knowledge Management, 7(3), pp. 129-138. 
[36] Cao, M., Vonderembse, M., Zhang, Q. and RaguNathan, T.S. (2010). Supply chain collaboration: conceptualisation and instrument development, International Journal of Production Research, 48(22), pp. 6613-6635.

[37] Jayaram, J \& Pathak, S. (2013) A holistic view of knowledge integration in collaborative supply chains, International Journal of Production Research, 51(7), pp. 1958-1972.

[38] Fugate, B. S., Stank, T. P., \& Mentzer, J. T. (2009). Linking improved knowledge management to operational and organizational performance. Journal of Operations Management, 27(3), pp. 247-264.

[39] Li, X. and Hu, J. (2012). "Business Impact Analysis Based on Supply Chain's Knowledge Sharing Ability”, Procedia Environmental Sciences 12, pp. 1302-1307.

[40] Biotto, M., De Toni, A. and Nonino, F. (2012) "Knowledge and cultural diffusion along the supply chain as drivers of product quality improvement", The International Journal of Logistics Management, 23(2), pp.212-237.

[41] Lee, H.L., 2004. The triple-A supply chain. Harvard Business Review, 82(10), pp.102-113.

[42] Cheung, C.F., Cheung, C.M. \& Kwok, S.K. (2012). A Knowledge-based Customization System for Supply Chain Integration. Expert Systems with Applications 39, pp. 39063924.

[43] Myers, M. and Cheung, M. (2008). Sharing Global Supply Chain Knowledge. MIT Sloan Management Review, 49(4), 66-73.

[44] Hult, G.T.M., Ketchen, D. \& Arrfelt, M. (2007). Strategic Supply Chain Management: Improving Performance through a Culture of Competitiveness and Knowledge Development. Strategic Management Journal, 28(10), pp.1035-1052.

[45] Beske, P., Land, A. and Suering, S. (2014). "Sustainable supply chain management practices and dynamic capabilities in the food industry: A critical analysis of the literature." International Journal of Production Economics 152, pp. 131-143.

[46] Swafford, P., Ghosh, S. \& Murthy, N. (2008). Achieving supply chain agility through IT integration and flexibility Int. Journal of Production Economics, 116, pp. 288-297.

[47] Gimenez, C. van der Vaart, T and van Donk, P. (2012) "Supply chain integration and performance: the moderating effect of supply complexity", International Journal of Operations \& Production Management, 32(5) 5, pp.583-610. [48] Liu, H, Ke, W., Wei, K. and Hua, Z. (2013). "The impact of IT capabilities on firm performance: The mediating roles of absorptive capacity and supply chain agility." Decision Support Systems 54(3), pp. 1452-1462.

[49] Armstrong, C. and Shimizu, K. (2007), "A Review of Approaches to Empirical Research on the Resource Based View of the Firm", Journal of Management, 33(6), pp. 959989.

[50] Lockett, A., Thompson, S. and Morgenstern, U. (2009), "The development of the resource-based view of the firm: A critical approach", International Journal of Management Reviews, 11(1), pp. 9-28.
[51] Wernerfelt, B. (1984), The Resource-Based View of the Firm, Strategic Management Journal, 5(2), pp. 171-80.

[52] Barney, J. (1996), "The Resource-Based Theory of the Firm", Organization Science, 7(5), pp. 469-76.

[53] Barney, J. (1991), "Firm Resources and Sustained Competitive Advantage", Journal of Management, 17(1), pp. 99-119.

[54] Grant, R.M. (1996). Toward a knowledge-based theory of the firm. Strategic Management Journal, 17, pp. 109-122. [55] Conner, K.R. and Prahalad, C.K., 1996. A resourcebased theory of the firm: Knowledge versus opportunism. Organization Science, 7(5), pp.477-501.

[56] Kogut, B. and Zander, U., 1992. Knowledge of the firm, combinative capabilities, and the replication of technology. Organization science, 3(3), pp.383-397.

[57] Samson, D. and Gloet, M. (2017). Integrating performance and risk aspects of supply chain design processes. Production Planning and Control, forthcoming. [58] Yin, R.K. (2003). Applications of case study research, $3^{\text {rd }}$ ed. Sage, Newbury Park.

[59] Yin, R.K. (2014). Case study research: design and methods, $5^{\text {th }}$ ed., Sage, Thousand Oaks.

[60] Safizadeh, M. H., Ritzman, L. P. and Mallick, D. (2000). Revisiting alternative theoretical paradigms in manufacturing strategy. Production and Operations Management, 9(2), pp. 111-126.

[61] Barney, J. (1996). The Resource-Based Theory of the Firm. Organization Science, 7(5), 469-76.

[62] Teece, D., 2009. Dynamic Capabilities and Strategic Management: Organizing for Innovation and Growth. Oxford: Oxford University Press.

[63] Carrillo, J. and Gaimon, C. (2004). Managing Knowledge-Based Resources Under Uncertainty, Management Science, 50(11), pp. 1504-1518.

[64] McMullen, J.S. and Shepherd, D.A. (2006). Entrepreneurial action and the role of uncertainty in the theory of the entrepreneur. Academy of Management Review, 31(1), pp.132-152.

[65] Bratianu, C. and Bolisani, E. (2015). Knowledge strategy: An integrated approach for managing uncertainty. In European Conference on Knowledge Management, pp. 169-177. Academic Conferences International Limited. 